\title{
Critical Impact Energy of Flat Nose Hard Projectile Causing Early Scabbing in Concrete Slab
}

\author{
Qadir Bux alias Imran Latif*, Ali Al-Nuaimi**, Ahmad Jamrah* \\ * Department of Civil and Architectural Engineering, College of Engineering, University of Buraimi (UoB), Oman \\ ** Department of Civil and Architectural Engineering, College of Engineering, Sultan Qaboos University (SQU), Oman
}

\begin{tabular}{|c|c|}
\hline Article Info & ABSTRACT \\
\hline Article history: & In this paper, 2D numerical simulation finite element analysis has been \\
\hline Received Jun 10, 2014 & carried out for critical impact energy of flat nose hard projectile causing early \\
\hline Revised Aug 20, 2014 & elastic assumption of the classic wave equation, using ABAQUS software. \\
\hline Accepted Aug 28, 2014 & $\begin{array}{l}\text { Numerical simulation predictions were compared with experimental data and } \\
\text { with the well established UMIST, NDRC, Li and Reid formulae and found }\end{array}$ \\
\hline Keyword: & $\begin{array}{l}\text { comparable and reliable. The influence of hard projectile diameter with flat } \\
\text { nose, and concrete wall thickness on critical impact energy was also }\end{array}$ \\
\hline Concrete & investigated. It was found that the effect of critical impact energy is directly \\
\hline $\begin{array}{l}\text { Critical impact energy } \\
\text { Flat nose }\end{array}$ & $\begin{array}{l}\text { proportional to the thickness of concrete target and inversely proportional to } \\
\text { the diameter of flat nose hard projectile. }\end{array}$ \\
\hline
\end{tabular}

Copyright $(0) 2014$ Institute of Advanced Engineering and Science.

Hard projectile

Scabbing

Simulation

All rights reserved.

\section{Corresponding Author:}

Qadir Bux alias Imran Latif,

Department of Civil and Architectural Engineering,

College of Engineering, University of Buraimi (UoB),

P.O. Box 890, P.C. 512, Al - Buraimi, Oman.

Email: imranqazi37@gmail.com,imran.1@uob.edu.om

\section{INTRODUCTION}

The investigation of scabbing phenomenon was first introduced by [1]. Kumar and Davis (1958) analysed the scabbing phenomenon in term of wave propagation effects using one-dimensional analysis approach [2]. Hwang and Davis (1960) extended the approach and interpreted it into contour plotting method for further studies of non-linear materials due to tensile reflection. However, scabbing in metal slabs is normally associated with high strain rates and has brittle features because, the ductility of the metal decreases with the increase of strain rate [3].

Scabbing phenomena in concrete structures have attracted large attention due to the growing applications of concrete structures under impact and blast loads in both civil and military engineering. Scabbing is caused by the tensile stress reflected from the impact-induced compressive stress wave on the top and distal free surfaces of the concrete slab. Hughes (1984) attributed the scabbing in a reinforced concrete to two different mechanisms, i.e. the reflected tensile stress wave and the shear cone [4]. Dinic and Perry (1990) mentioned that scabbing may occur before shear plug formation or as a result of shear plug movement [5]. Kojima (1991) and Sugano et al., (1993) observed that the formation of cone shear is closely associated with the occurrence of scabbing in concrete target [6], [7]. Stephenson et al., (1978) found that there exists a minimal thickness of the concrete target for preventing scabbing (i.e. scabbing limit) against the impact by a hard projectile [8].

Numerical simulation is a common method used to study scabbing phenomenon and provide detailed information for the scabbing process, which might be used to improve the design of concrete target. Kusano et al., (1992) and Magnier and Donze (1998) employed discrete element method (DEM) to model scabbing phenomenon and reasonably good agreements with the selected empirical formula were reached [9], 
[10]. Leppanen (2006) simulated scabbing phenomenon using smooth particle hydrodynamic (SPH) technique in AUTODYN and successfully showed the formation of scabbing. However, despite excessive computational resources for the numerical simulation of a dynamic fragmentation problem, uncertainty increases due to the needs of more material parameters [11].

In general, the limited studies have been found on critical impact energy for scabbing phenomenon. Critical impact energy is the dominant cause of scabbing in concrete slabs [12], [13]. When a hard projectile impact with concrete slab, the critical impact energy of the projectile is the main reason that makes concrete slab deforms [14]. In this paper, 2D FE numerical simulation investigation has been conducted based on stress wave propagation and free-surface reflection theory on elastic model. Furthermore, the influence of flat nose hard projectile diameter $(d)$ and concrete thickness $(H)$ on critical impact energy was also investigated.

\section{STRESS WAVE PROPAGATION IN CONCRETE}

Kennedy (1976) described scabbing phenomenon as the ejection or peeling of fragments from the distal free surface of the concrete slab after it is subjected to projectile impact on its front face [15]. Generally, scabbing mode can be classified into two types [6], [7], i.e. Scabbing: massive ejection of plug or fragments on the distal side of the target shown in Figures 1(a) and 2(a) or Just (incipient) scabbing: formation of plug or fragments on the distal side of the target with minor ejections shown in Figures 1(b) and 2(b).

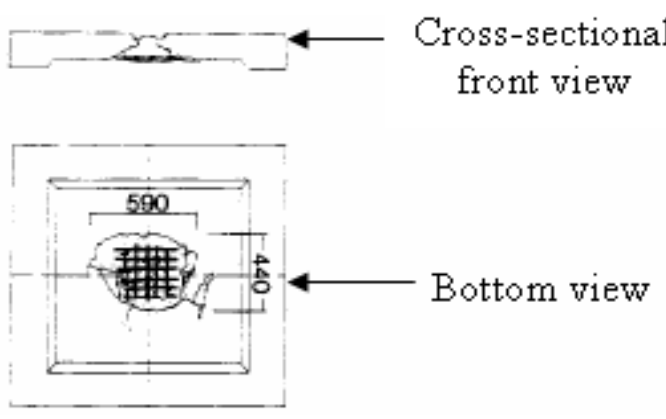

(a)

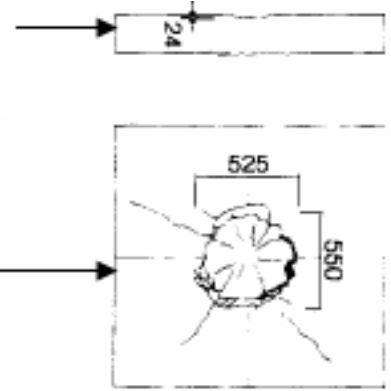

(b)

Figure 1. Experimental illustration of (a) scabbing, (b) just scabbing [7]

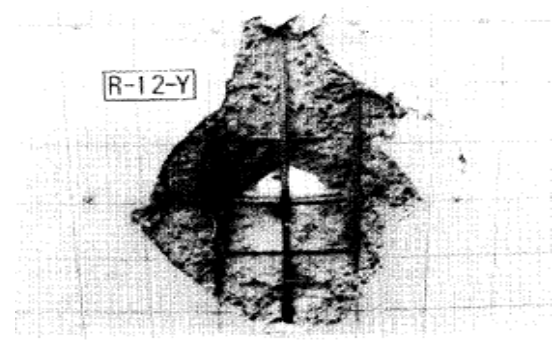

(a)

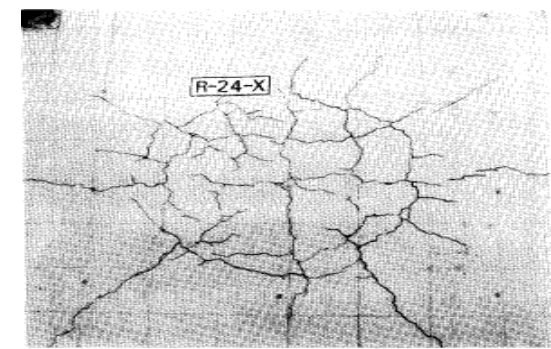

(b)

Figure 2. Post-experimental of (a) scabbing, (b) just scabbing [6]

Scabbing occurs mainly due to the excessive resultant tensile stress. In a one-dimensional brittle rod, scabbing may occur when the resultant tensile stress is equal or greater than the tensile strength of the material. For a panel target, the formation of a massive plug may also need to overcome shear resistance, which is clearly shown by experimental evidences in [6], [7]. When a concrete member is subjected to dynamic loading, a stress wave will propagate through it. The stress wave propagates in the longitudinal and the transverse directions in the structure [14], [16]. By using constitutive laws, equilibrium and compatibility, the classic wave equation in one dimension for elastic materials can be derived as shown in Figure (3). In real structures when the projectile hits the concrete, the concrete behaviour is far from elastic, and the elastic wave equations are not accurately valid. However, the elastic assumption of the classic wave equation illustrates phenomena for concrete in dynamic loading [14], [16]. When a compressive stress wave in 
concrete is propagating it will reflect at the boundary. If the boundary is air, the reflected stress will be equal to the incident stress but with opposite sign. This means that the reflected wave will propagate as a tensile wave, since concrete is very weak in tension; the reflected wave can cause scabbing. The reflected and transmitted stress waves amplitudes and velocities depend on the concrete [14], [16].

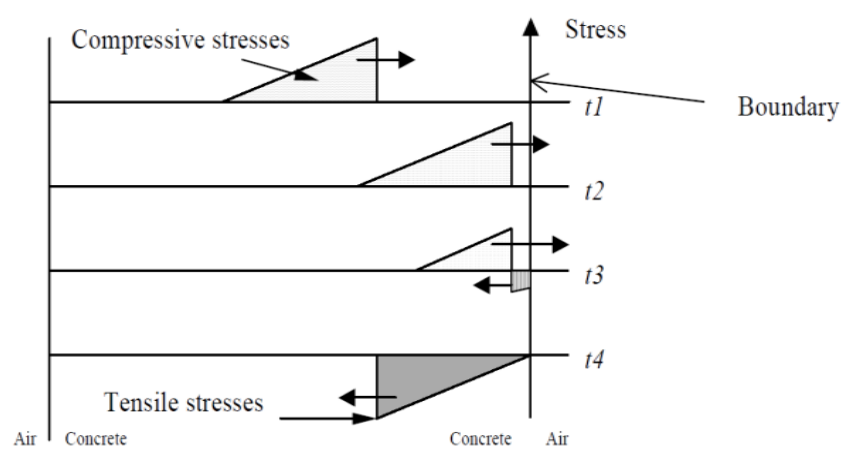

Figure 3. Stress wave propagation in a free boundary concrete slab on impact of hard projectile [14], [16]

\section{NUMERICAL SIMULATION}

A 2-Dimensional a-symmetric numerical simulation was conducted using ABAQUS finite element software package on experimental data of Bainbridge (1988) and Li and Reid (2006) [17], [18]. Attentions are paid on the early stage of the compressive stress wave propagation in concrete slab following a local impact by a hard projectile, and the reflections of the compressive stress wave on the free distal surface of the concrete slab causing early scabbing. The simulation study was conducted for required critical impact energy of flat nose hard projectile causing early scabbing in concrete slab. Furthermore, the effect of diameter of flat nose hard projectile, and effect of thickness of concrete slab on critical impact energy required to causing early scabbing were also analysed.

\subsection{Analysis Code}

The Dynamic Analysis using ABAQUS/Explicit code depends on: Inertia effect, and direct integration system. The direct integration system is mainly used in non-linear dynamic analysis. The significance of direct integration dynamics is that, the global equations of motion of system must be integrated through time. In ABAQUS/Explicit, the direct-integration dynamic uses the central-difference operator. The displacements and velocities are calculated in-terms of quantities at the beginning of an increment, the global mass and stiffness matrices do not need be formed and inverted. The size of the time increment in an explicit dynamic analysis is limited, because the central-difference operator is only conditionally stable. The stability limit for the central-difference method, (the largest time increment that can be taken without the method generating large, rapidly growing errors) is closely related to the time required for a stress wave to cross the smallest element dimension in the model. Thus, the time increment in an explicit dynamic analysis which can be very short if the mesh contains small elements or if the stress wave speed in the material is very high. In the Lagrangian description, the numerical mesh distorts with the material movement. During the Lagrangian phase of the time increment nodes are assumed to be temporarily fixed within the material, and elements deform with the material [14], [19].

\subsection{Model Development}

The numbers of simulations have been carried out on plain concrete slabs impacted with flat nose hard projectile in normal direction. For the explanation, one of the simulations is described in detail. The concrete slab having thickness of $(\mathrm{H}=600 \mathrm{~mm}), 36.0 \mathrm{MPa}$ unconfined compressive stress $\left(\mathrm{f}_{\mathrm{c}}\right)$, and 28.0 GPa young's modulus (E) is modelled as an elastic body (based on elastic section of the stress-strain curve as shown in Figure 4) with 960 linear triangular elements (Type CAX3) by structural meshing technique. The front surface of a fully clamped concrete slab is impacted by a flat nose rigid projectile of $305 \mathrm{~mm}$ in diameter having mass $300 \mathrm{~kg}$, impacted with $143 \mathrm{~m} / \mathrm{sec}$ velocity is modelled as a rigid body with discrete rigid linear line elements with total 20 linear line elements (Type RAX2). 


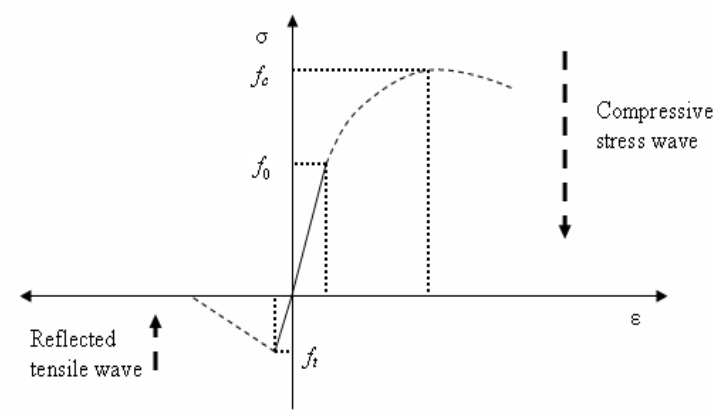

Figure 4. Uniaxial behaviour of concrete material

The mechanical properties of concrete slabs and missile are presented in Table 1 for critical impact energy analysis, and the effect of diameter of flat nose hard projectile, and effect of thickness of concrete slab on critical impact energy required to cause early scabbing.

Table 1. Mechanical Properties of Concrete and Projectile

\begin{tabular}{|c|c|c|c|c|c|}
\hline \multicolumn{2}{|c|}{ Concrete } & \multicolumn{4}{|c|}{ Flat Nose Hard Projectile } \\
\hline $\begin{array}{l}\text { Thickness } \\
\text { (mm) }\end{array}$ & $\begin{array}{c}\text { Unconfined } \\
\text { Compressive Strength } \\
\text { Fc (MPa) }\end{array}$ & H/d Ratio & $\begin{array}{l}\text { Dia. of Projectile d } \\
(\mathrm{mm})\end{array}$ & $\begin{array}{c}\text { Mass of } \\
\text { Projectile M } \\
\text { (kg) }\end{array}$ & $\begin{array}{l}\text { Striking Velocity } \\
\qquad V_{\mathrm{s}}(\mathrm{m} / \mathrm{s})\end{array}$ \\
\hline $50.8-600$ & $24.15-46.6$ & $0.69-14.86$ & $17.5-305$ & $0.92-309$ & $28.98-427$ \\
\hline
\end{tabular}

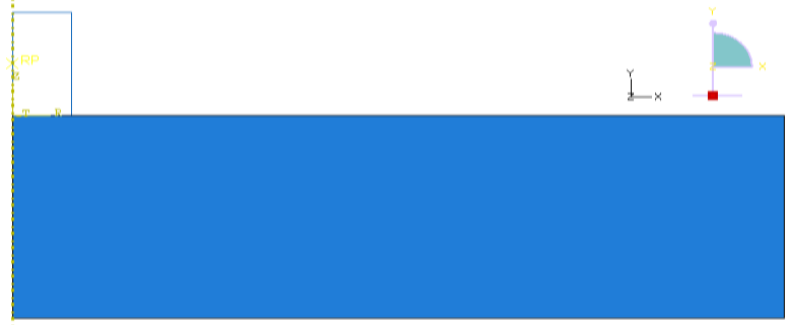

Figure 5. Finite element model

A distortion control is applied to avoid disproportional distortion of elements in the target mesh. The interested simulation time is calculated based on the reflecting time of the impact-induced compressive stress wave from the distal free surface of the target, i.e. $\frac{H}{c}<t<\frac{2 H}{c}$, where $H$ is the length of the target thickness and $c=\sqrt{E / \rho}$ is the elastic stress wave speed in the target, $(E)$ and $(\rho)$ are Young's modulus and density of the target [14].

\section{RESULTS AND DISCUSSION}

For validation purpose, corresponding predictions based on numerical simulation, UMIST, NDRC, Li and Reid formulae compared with experimental data of Bainbridge [17], [18].

\subsection{Critical Impact Energy}

The visualized result shows that the model clearly provides loading in the form of strains/stresses in the concrete slab due to the projectile impact. Figure 6(a-d) shows nice propagation of impact-induced compressive stress wave and its superposition with the reflected tensile stress wave from the free distal surface in concrete slab. The wave front is approximately a plane. The reflected tensile stress is superimposed 
to the incoming compressive stress to produce a region of net tensile stress. When the net tensile stress is equal to or greater than the tensile strength of the concrete, tensile failure occurs at those locations, which subsequently lead to the occurrence of scabbing.

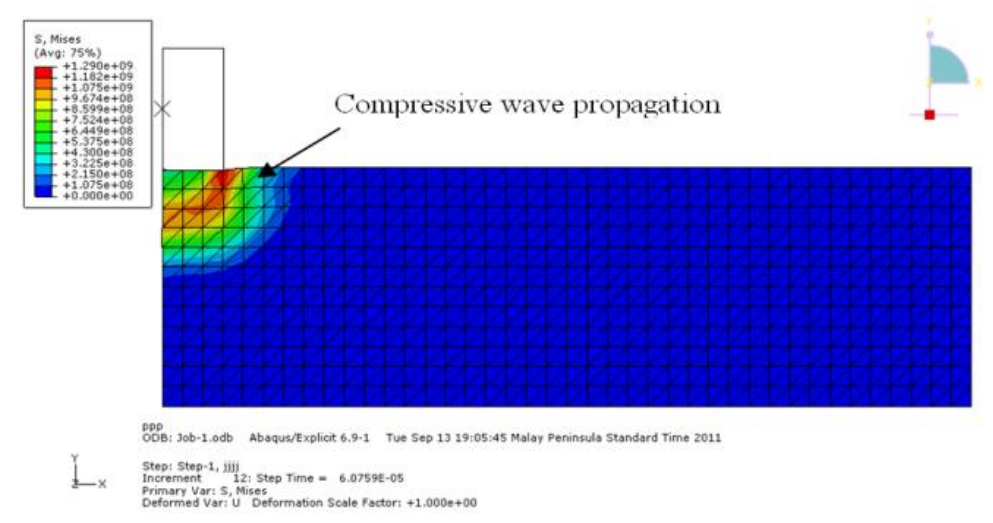

Figure 6 (a). Compressive wave propagation in ax-symmetric 2D simulation problem for occurrence scabbing at time $6.07 \mathrm{e}-05 \mathrm{~s}$

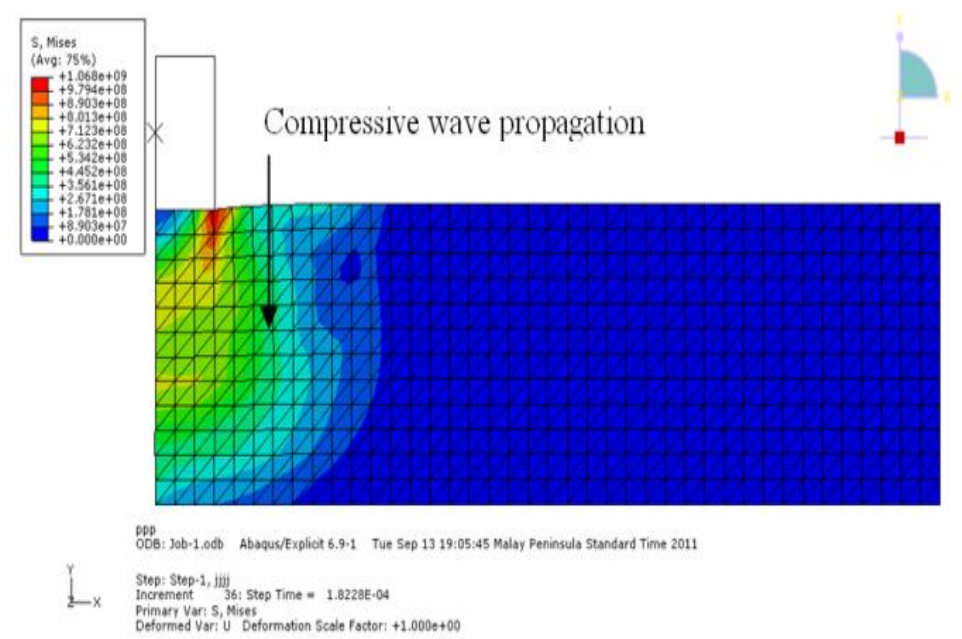

Figure 6 (b). Compressive wave propagation in ax-symmetric 2D simulation problem for occurrence scabbing at time $1.82 \mathrm{e}-04 \mathrm{~s}$.

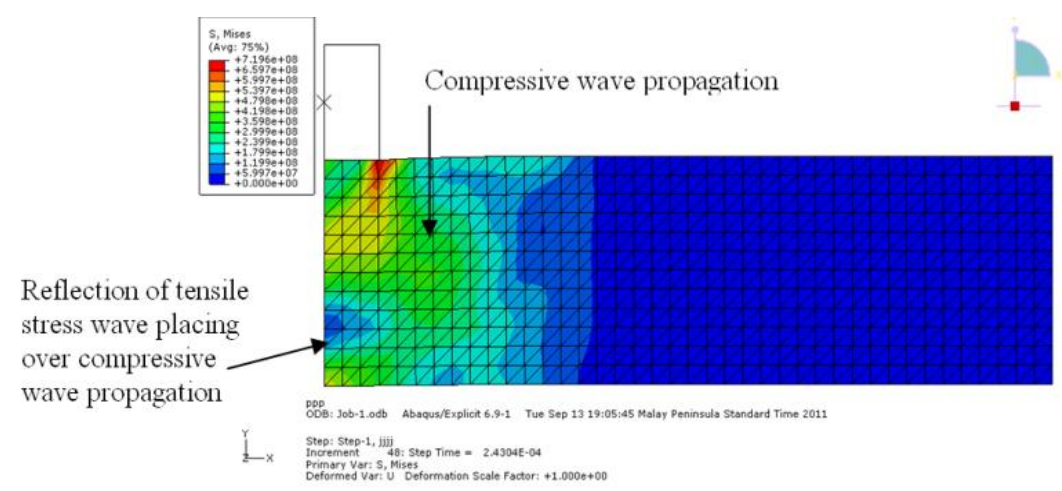

Figure 6 (c). Reflection of tensile stress wave from distal surface placing over compressive wave propagation in ax-symmetric $2 \mathrm{D}$ simulation problem for occurrence scabbing at time $2.43 \mathrm{e}-04 \mathrm{~s}$ 


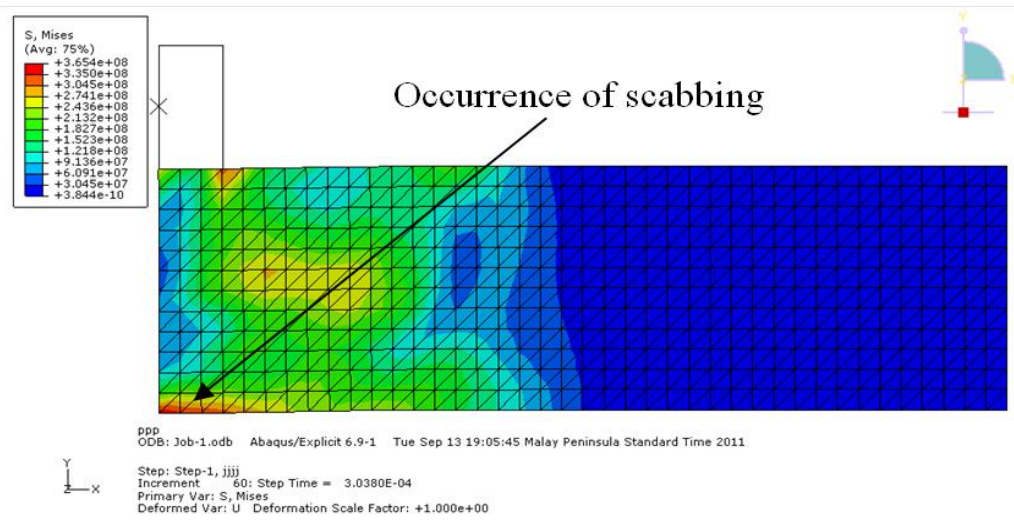

Figure 6 (d). Tensile stress wave from distal surface became equal to the tensile strength of concrete causing scabbing at distal face in ax-symmetric $2 \mathrm{D}$ simulation problem for occurrence scabbing at time $3.03 \mathrm{e}-04 \mathrm{~s}$

Figure 7 shows the time history of impact energy for occurrence of critical impact energy in three stages. It is clear that the impact energy at the initial stage compressive stress wave propagates into concrete target phase one, followed by reflection of tensile stress wave from distal face of concrete, phase two. At the end, when the net tensile stress becomes equal to or greater than the tensile strength of the concrete, tensile failure occurs in concrete causing scabbing at distal face.

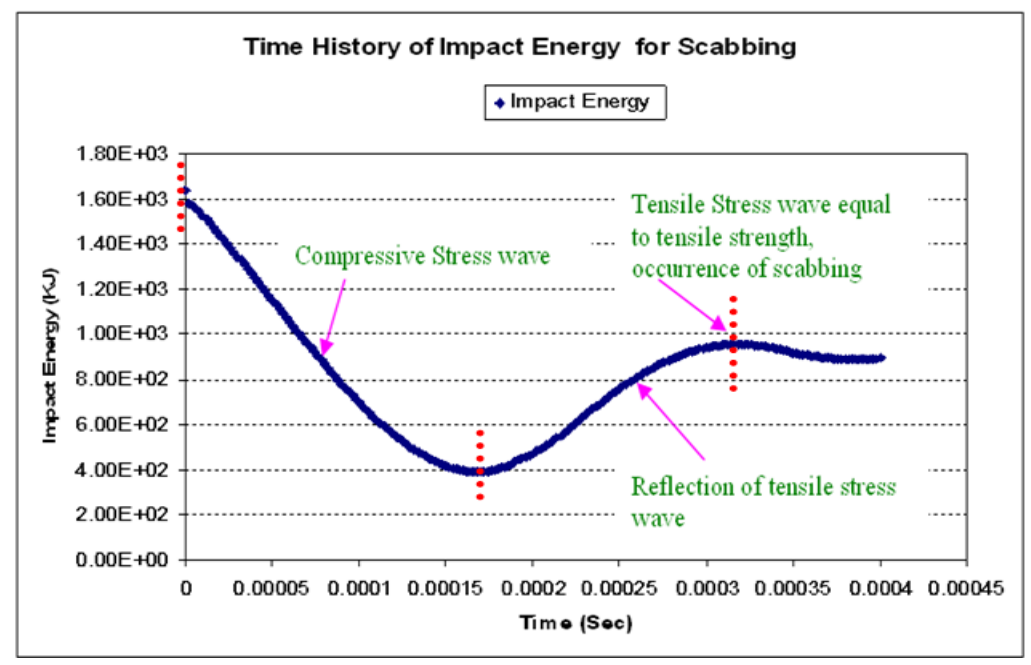

Figure 7. Time history of impact energy from compressive wave propagation to reflection of tensile stress wave from distal surface until occurrence of scabbing

The numerical simulation results examined for the prediction of minimum required critical impact energy of flat nose hard missile to scabb the concrete target. The results obtained from numerical simulations are relatively close to the experimental data and other well established formulae such as UMIST, NDRC, Li and Reid. In case of $(0.69 \leq \mathrm{H} / \mathrm{d} \leq 3.0)$, it was found that the numerical simulation results are most accurate (closest to experiemental data) followed by NDRC, Li and Reid, and UMIST predictions. It can be argued that UMIST, NDRC Li and Reid formulae produced under prediction results within this range.

In case of $(3.0 \leq \mathrm{H} / \mathrm{d} \leq 6.0)$ simulation results are closer as compared to experiemental data. Among UMIST, NDRC, Li and Reid formulae, Li and Reid formula predicts closer results followed by NDRC and UMIST respectively. 


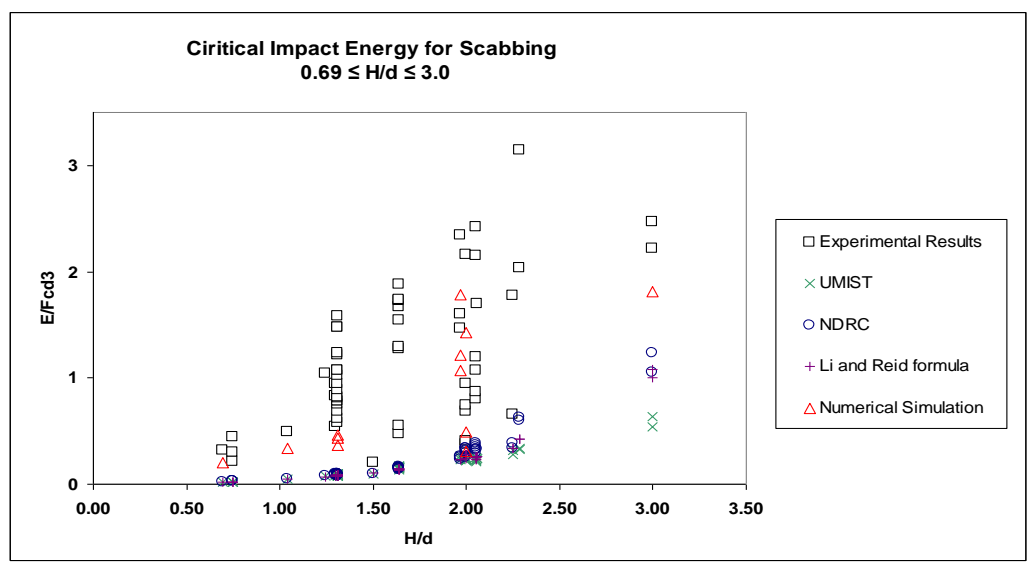

Figure 8(a). The results of newly developed formulae and numerical simulations comparedwith UMIST, NDRC and Li and Reid predictions $(0.69 \leq \mathrm{H} / \mathrm{d} \leq 3.0)$

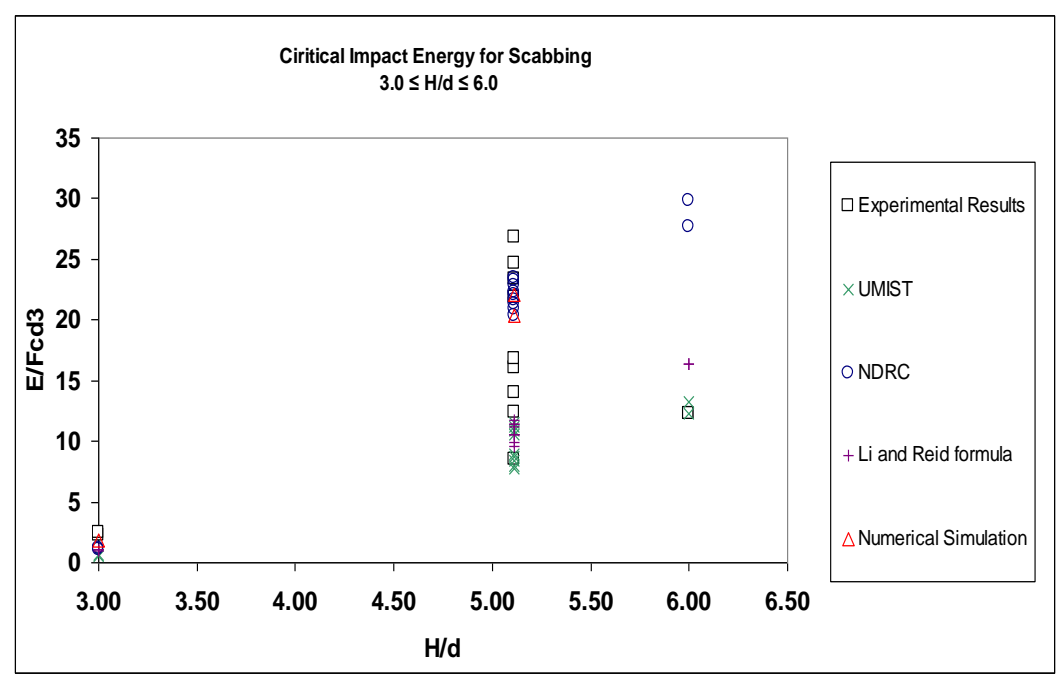

Figure 8(b). The results of newly developed formulae and Numerical simulations comparison with UMIST, $\mathrm{NDRC}$ and $\mathrm{Li}$ and Reid formulae predictions within the range of $(3.0 \leq \mathrm{H} / \mathrm{d} \leq 6.0)$

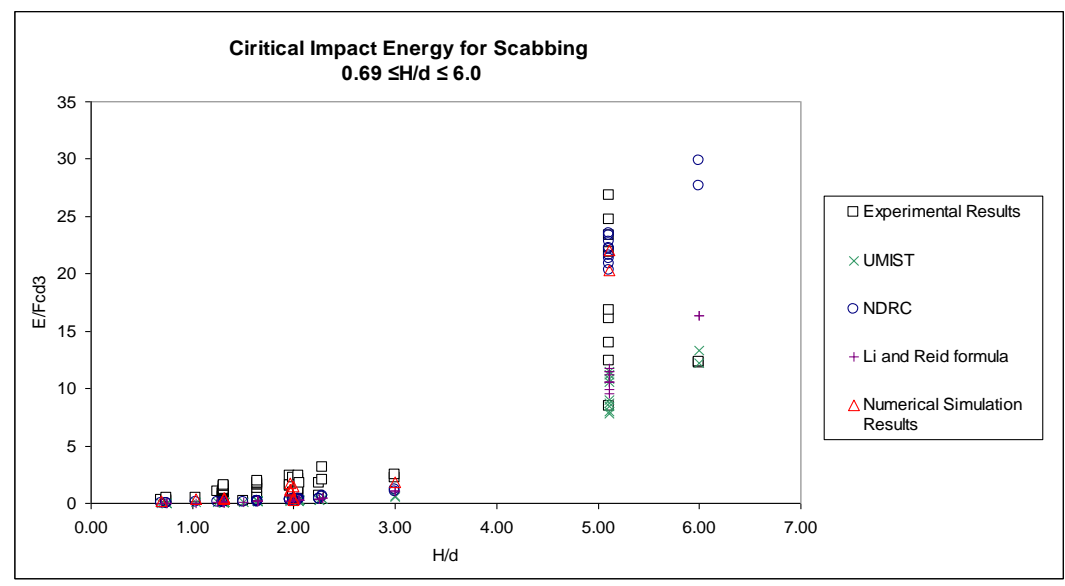

Figure 8(c). The results of newly developed formulae and numerical simulations compared with UMIST, NDRC and $\mathrm{Li}$ and Reid formulae predictions $(0.69 \leq \mathrm{H} / \mathrm{d} \leq 6.0)$ 
Comparison with other established formulae shows that the UMIST formulae predict the lowest values of the critical impact energy for scabbing compared with other formulae. The predicted results are consistently lower than the experimental results. Within the range of $(0.69 \leq \mathrm{H} / \mathrm{d} \leq 6.0)$, among all simulations results are more accurate, followed by Li and Reid formula and NDRC predict good results as compared to UMIST formula. It is observed that the simulation results are consistently closer to experimental results and produced a similar general trend of experimental results in the whole range of experimental data presented in Figure $8(\mathrm{a}, \mathrm{b}, \mathrm{c})$. Therefore, numerical simulation is conservative and reliable as compared to UMIST, NDRC, Li and Reid formulae within its limitations at lower impact velocities.

\subsection{Effect of Projectile Diameter (d) on Critical Impact Energy for Early Scabbing}

The effect of diameter of flat nose hard projectile was studied on critical impact energy for early scabbing. The influence of diameter of projectile on the required critical impact energy for scabbing of concrete target was analysed with the help of numerical simulation, while keeping all other parameters and properties of concrete slab and projectile same. Two simulations have been carried out to explore the effect of different diameters $200 \mathrm{~mm}$ and $300 \mathrm{~mm}$ of projectile with $300 \mathrm{~kg}$ mass at velocity of $100 \mathrm{~m} / \mathrm{sec}$, and $240 \mathrm{~kg}$ mass at velocity of $72 \mathrm{~m} / \mathrm{sec}$ respectively.

Figure 9 and 10 compare the simulated results of the effect of diameter of projectile on impact energy for scabbing. It is clearly shown that the greater diameter of flat nose hard projectiles requires less impact energy and time for occurrence of scabbing in concrete target. On the other hand small diameter of flat nose hard projectiles requires more impact energy and time for occurrence of scabbing in concrete target as compared to the large diameter of projectile. In case of early scabbing, it shows that the impact energy is inversely proportional to the diameter of flat nose hard missile.

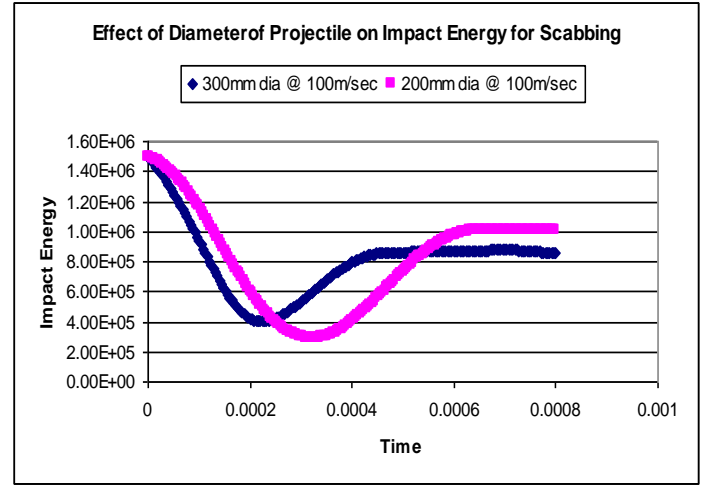

Figure 9. The simulation results of effect of diameter on impact energy for scabbing at $100 \mathrm{~m} / \mathrm{sec}$

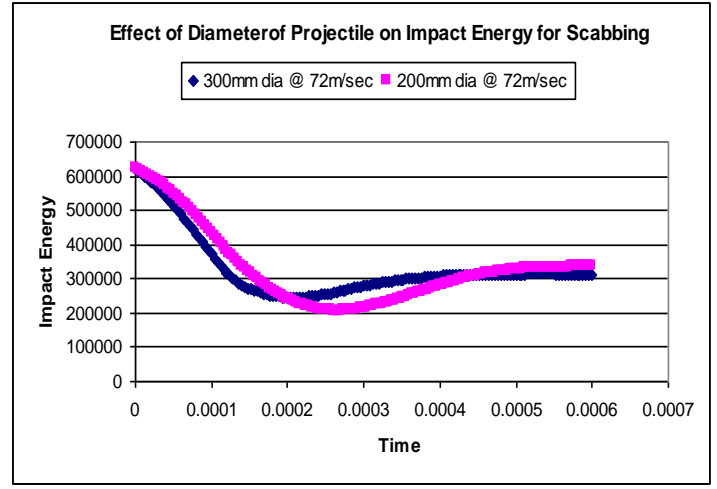

Figure 10. The simulation results of effect of diameter on impact energy for scabbing at $72 \mathrm{~m} / \mathrm{sec}$

\subsection{Effect of Concrete Slab Thickness (H) on Critical Impact Energy for Early Scabbing}

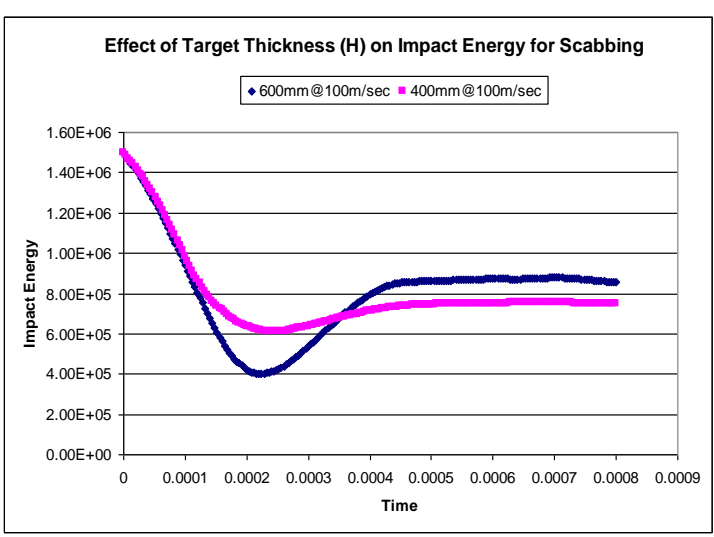

Figure 11. The simulation results of effect of target thickness $(\mathrm{H})$ on impact energy for scabbing at $100 \mathrm{~m} / \mathrm{sec}$

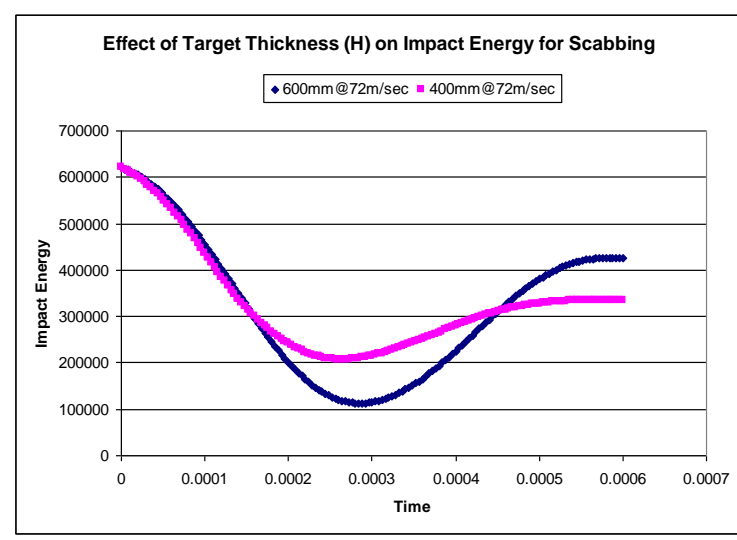

Figure 12. The simulation results of effect of target thickness $(\mathrm{H})$ on impact energy for scabbing at $72 \mathrm{~m} / \mathrm{sec}$ 
The effects of target thickness $(\mathrm{H})$ of concrete also have influence on impact energy for scabbing. By maintaining all other parameters same, two simulations were carried out to explore the effect of target thickness $(\mathrm{H})$ of $600 \mathrm{~mm}$ and $400 \mathrm{~mm}$ of projectile at velocity of $100 \mathrm{~m} / \mathrm{sec}$, and $72 \mathrm{~m} / \mathrm{sec}$ respectively.

Figure 11 and 12 compare the simulated results of target thickness $(\mathrm{H})$ at $\mathrm{H}=600 \mathrm{~mm}$ and $\mathrm{H}=$ $400 \mathrm{~mm}$ respectively. It was observed that the lower concrete thickness requires less impact energy and time for scabbing of concrete targets as compared to higher target thickness. It concludes that the impact energy is directly proportional to the thickness of concrete target $(\mathrm{H})$.

\section{CONCLUSION}

A numerical simulation study was conducted to predict the early stage of the scabbing occurrence caused by the reflected tensile wave. The influence of the relative target thickness $(H / d)$, over the critical impact energies of occurrence scabbing has been explored by comparing numerical simulation results with well established formulae (e.g: UMIST, NDRC, Li and Reid) and with experimental results. Generally, the numerical simulation produced encouraging prediction which is consistent and follows a general trend of experimental results as compared to $\mathrm{Li}$ and Reid, UMIST and NDRC formulae, at lower relative target thickness and low impact velocity. The effect of flat nose projectile diameter (d) and target thickness $(\mathrm{H})$ were investigated; it was found that the greater diameter of flat nose hard projectiles requires less impact energy for occurrence of scabbing in concrete target. On the other hand small diameter of flat nose hard projectiles requires more impact energy for occurrence of scabbing in concrete target as compared to the large diameter of projectile. In case of effect of target thickness $(\mathrm{H})$ concrete response is opposite to the effect of flat nose projectile diameter, it is observed that the lower concrete thickness requires less impact energy for scabbing of concrete targets as compared to higher target thickness. It can be concluded that the impact energy is directly proportional to the thickness of concrete target $(\mathrm{H})$, and inversely proportional to the (d) diameter of flat nose hard projectile.

\section{ACKNOWLEDGEMENTS}

The authors would like to thank University Tun Hussein Onn Malaysia (UTHM) for supporting this research through International Students Scholarships.

\section{REFERENCES}

[1] Hopkinson D. B., "A Method for measuring the pressure in the detonation of high explosive or by impact of bullets," Phil. Trans. Roy. Soc., 1914.

[2] Kumar S., et al., "Elastic-plastic analysis of scabbing in materials," J. Franklin Inst., 1958, Vol. 265, No. 5, pp. 371-383.

[3] Hwang S. Y., et al., "Graphical analysis of the formation of shock fronts in materials," J. Mech. Phys. Solids, 1960, Vol. 8, pp. 52-65.

[4] Hughes G. "Hard missile impact on reinforced concrete," J. Nuc. Eng. Des., 1984, Vol. 77, pp.23-35.

[5] Dinic G., et al., "Shear plug formation in concrete slabs subjected to hard impact," J. Eng. Frac. Mech., 1990, Vol. 35, No. 1-3, pp. 343-350.

[6] Kojima I., "An experimental study on local behaviour of reinforced concrete slabs to missile impact," J. Nuc. Eng. Des., 1991, Vol. 130, pp.121-132.

[7] Sugano T., et al., "Local damage to renforced concrete structures caused by impact of aircraft engine missiles Part1. Test program, method and results," Nuc. Eng. Des., 1993, Vol. 140, pp. 387-405.

[8] Stephenson A. E., et al., "Full scale tornado-missile impact test," Nucl. Eng. Des., 1978, Vol. 46, pp. 123-143.

[9] Kusano N., et al., "Impulsive local damage analyses of concrete structure by the distinct element method," J. Nuc. Eng. Des., 1992, Vol. 138, pp. 105-110.

[10] Magnier S. A., et al., "Numerical simulations of impacts using a discrete element method," J. Mech. Cohes-Frict. Mater., 1998, Vol. 3, pp. 257-276.

[11] Leppanen J., "Concrete subjected to projectile and fragment impacts: Modelling of crack softening and strain rate dependency in tension," Int. J. Impact Eng., 2006, Vol. 32, pp. 1828-1841.

[12] Rahman I. A., et al., "Simulation Study on Effect of diameter and CRH Ratio of Ogive Nose Hard Missile on Required Critical Impact Energy for Penetration of Concrete Targets," Journal of International Review on modelling and Simulations (IREMOS), 2011, Vol. 4, No. 3, pp. 1373-1381.

[13] Rahman I. A. A., et al., "Empirical Formula Prediction on Critical Impact Energy for Scabbing Phenomena on Concrete Structures," Applied Physics Research APR, 2010, Vol. 2, No. 2, pp. 192 - 197.

[14] Imran Latif Q. B. A., et al., "Impact Energy for Local Damage of Hard Projectile on Concrete Slab (Penetration, Scabbing and Perforation of Concrete Slab - Impact Engineering)," Monogram book, Lap Lambert Publisher, 2012. 
[15] Kennedy R. P., "A review of procedures for the analysis and design of concrete structures to resist missile impact effects,” J. Nuc. Eng. Des., 1976, Vol. 37, pp. 183-203.

[16] Leppanen J., "Concrete Structures Subjected to Fragment Impacts (Dynamic Behaviour and Material Modelling)," Thesis for Doctor of Philosophy, Department of Structural Engineering and Mechanics Concrete Structures, Chalmers University of Technology, 2004.

[17] Bainbridge P., "World Impact Data-S.R.D.," Impact Database Version Pre 3i, 1988.

[18] Li Q. M., et al., "Critical impact energies for scabbing and perforation of concrete target," J. Nuc. Eng. Des., 2006, Vol. 236, pp. 1140-1148.

[19] Hibbitt, et al., “Inc. ABAQUS/EXPLICIT Online User's Manual,” Version 6.4., 2005.

\section{BIOGRAPHIES OF AUTHORS}

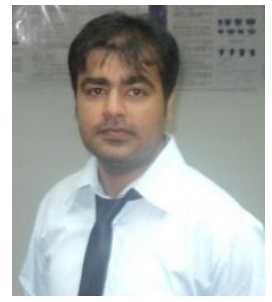

Dr. Qadir Bux alias Imran Latif was born at Nawabshah, on 08th of October 1982. He did his bachelor degree in Civil Engineering from Quaid-e-Awam University of Engineering Science and Technology (QUEST, Nawabshah, Sindh, Pakistan (2004), and completed his PhD in Civil Engineering at The University Tun Hussein Onn Malaysia (UTHM) (2012). He worked with Private Engineering Consultant firms for Four (4) years. Currently working as Assistant Professor at University of Buraimi (uob) Oman. The research interest is in Protective Technology, Impact Engineering, Modelling and Simulation, Structural Dynamics, FEA, Sustainable Engineering. He is an active researcher and has produced over 12 technical papers during PhD. Dr. Qadir Bux alias Imran Latif has professional membership with Pakistan Engineering Council (PEC) and with International Association of Engineers (IAENG). International Association of Protective Structures (IAPS)

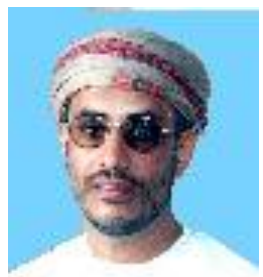

Assoc. Prof. Dr. Ali Al Muaimi is an Associate Professor in Department of Civil and Architectural Engineering, at Sultan Qaboos Universty, Oman. He obtained his PhD from Glasgow University UK, his MSc. and BEng. (Civil) from the University of Southern California USA.

Prof. Dr. Ahmed Jamrah is an Dean of College of Engineering at University of Buraimi (uob) Oman. 